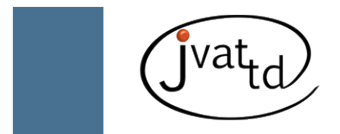

\title{
General characterization of venom from the Moroccan snakes Macrovipera mauritanica and Cerastes cerastes
}

Oukkache N (1), Lalaoui M (1), Ghalim N (1)

(1) Laboratory of Venoms and Toxins, Pasteur Institute of Morocco, Casablanca, Morocco.

\begin{abstract}
Ophidian envenomation accidents constitute a serious public health problem in many countries around the globe. Over 5 million such accident cases occur each year causing more than 100,000 deaths. In Africa, more than 20,000 deaths per year are registered while 400,000 envenomation victims retain severe and permanent functional sequelae. In Morocco, snakebites are frequent and of greater severity in children. They occur mostly in rural areas. The incidence of these bites remains poorly understood and vastly underestimated. The epidemiological data are not well known due to the absence of a national registry, whereas a significant proportion of envenomations receive only traditional treatment methods in nonmedical intensive care. This prompted us to investigate the enzymatic and biological properties of venom biochemical constituents from two of the most dangerous snake venoms in Morocco: Cerastes cerastes (Cc) and Macrovipera mauritanica $(\mathrm{Mm})$. Also, we studied the immune cross-reactivity of $\mathrm{Cc}$ and $\mathrm{Mm}$ venoms in comparison to that of another important dangerous Moroccan viper, Bitis arietans $(\mathrm{Ba})$, to identify the best candidates (venom or a mixture of venoms) for producing the most efficient and protective antivenom. In the present study, we report a preliminary venom characterization of $\mathrm{Cc}$ and $\mathrm{Mm}$ and the cross-reactivity that may exist between their venoms and $B a$. These venoms are known to be highly toxic and contain several proteins that differ by molecular weights. Interestingly, both $\mathrm{Cc}$ and $\mathrm{Mm}$ venoms are characterized by intense hemorrhagic and phospholipase $A_{2}$ activities and their ability to degrade the $a$ and $\gamma$ chains of fibrinogen. They display very low proteolysis through the casein test. After injection into mice, $\mathrm{Cc}$ and $\mathrm{Mm}$ induce myonecrosis in skeletal muscles, which most likely reflects direct action of myotoxins and indirect action of hemorrhagic molecules present in these venoms. In mice, this myonecrosis diminishes serum creatine phosphokinase (CPK) levels. As expected, $\mathrm{Cc}$ venom is immunogenic and induces highly protective antivenom against $\mathrm{Mm}$ and $\mathrm{Ba}$ venom antigens. This protective capacity is similar to that of the antivenom produced against the $\mathrm{Mm}$ venom.
\end{abstract}

Key words: Cerastes cerastes, Macrovipera mauritanica, snake venom, characterization, biological activities, cross-reaction.

\section{INTRODUCTION}

In North Africa, there are many species of front-fanged snakes but only a few are known to be dangerous. The foremost medically important species belong to the family Viperidae - Cerastes cerastes, $C c$ (horned viper); Macrovipera mauritanica, $\mathrm{Mm}$; and Bitis arietans, $\mathrm{Ba}-$ which were found capable of provoking severe hemorrhagic effects and the family Elapidae - i.e. Naja haje, $\mathrm{Nh}$ - most notably responsible for neurotoxic effects $(1,2)$. In Morocco, the majority of bites ( $53 \%$ of venomous animal bites and $7.2 \%$ of the estimated case fatality rate) occur in rural areas during the summer season (3). They are inflicted on the feet or ankles, most frequently during the evening when there is a greater probability of accidentally treading on 
a snake, sometimes at night while it is sleeping or moving. In Morocco, epidemiological data remain uncertain due to the non-declaration of envenoming cases and the absence of a national registry (4).

Venom glands are highly specialized tissues that possess a high capacity for protein secretion, and are a rich source of active proteins. Snake venoms are known to contain a complex mixture of pharmacologically active molecules, including organic and mineral components, small peptides and proteins. According to their major toxic effect, snake venoms may be conveniently classified as neurotoxic (Elapidae) or hemorrhagic (Viperidae). For instance, envenomings by Macrovipera mauritanica and Cerastes cerastes are characterized by hemorrhaging and abnormalities in the blood coagulation system, while the venom of the cobra Naja haje is mainly neurotoxic and affects the nervous system (5).

Viperidae snake venoms contain a number of different proteins (i.e. proteases, fibrinolytic enzymes) that induce alterations in the blood coagulation cascade and interfere with the normal hemostatic system and tissue repair, usually resulting in persistent bleeding. Studies on patients envenomed by various Viperidae species revealed a fascinating variation in clinical manifestations, ranging from neurological perturbations to increased capillary permeability and edema. These pathological outcomes may be due to the additive or synergistic effects of various enzymes and toxins present in the venom (6).

When taking measures against envenoming and concomitantly treating symptoms, specific therapy consisting of immunotherapy, using polyvalent antivenom, is still of great importance. When administered at the correct time, antivenom is considered to be the only efficient treatment of snake-envenomed patients. Experimental data and clinical observations have confirmed the rapid venom-neutralizing effect of potent antivenom $(1,7)$. However, producing an antivenom that is both effective and safe requires a more precise biological and biochemical characterization of the venom composition and analysis of its neutralization capacity. This prompts us to look for the venom biochemical constituents and to investigate the enzymatic and biological properties of two of the most dangerous snake venoms in Morocco: Cerastes cerastes and Macrovipera mauritanica. In this paper, we also studied the immune cross-reactivity between $\mathrm{Cc}$ and $\mathrm{Mm}$ venoms in comparison with $\mathrm{Ba}$ venom (another dangerous viper in Morocco) with the main objective of identifying the best candidates (venom or a mixture of venoms) and methodology for producing the most efficient and protective antivenom.

\section{MATERIAL AND METHODS}

\section{Venoms}

Venoms of Cerastes cerastes, Macrovipera mauritanica, Bitis arietans and Naja haje were extracted by manual stimulation, centrifuged, lyophilized and kept at $-20^{\circ} \mathrm{C}$ at the experimental center of the Pasteur Institute of Morocco.

\section{Protein Content}

The protein content of venoms samples was determined by the colorimetric method of Markwell et al. (8). Bovine serum albumin (BSA, Sigma) was used for standard assay.

\section{SDS-Polyacrylamide Gel Electrophoresis}

SDS-PAGE was carried out according to a previously described method (9). Samples were pretreated in reducing conditions (using $\beta$-mercaptoethanol).

\section{Determination of Lethal Dose ( $\left.\operatorname{LD}_{50}\right)$}

Swiss strain male mice aged 2 months and weighing 18-20 g were used. All the procedures involving animals were in accordance with the ethical principles in animal research adopted by the World Health Organization (10).

Lethal potency of venom (in $\mu \mathrm{g}$ per Swiss mice) was assessed intravenously (IV) as recommended by the World Health Organization (10). Increasing amounts were injected into Swiss strain male mice (groups of five mice), in final volumes of $500 \mu \mathrm{L}$. The mortality percentage was recorded 24 hours after injections. The lethal dose $\mathrm{LD}_{50}$ was determined according to the method described by the software package Prism 45 (GraphPad, Inc.).

\section{Proteolytic Activity}

Proteolytic activity was estimated using casein as substrate, according to the previously described method (11). Venoms were used at doses of 50, 100 and $200 \mu \mathrm{g}$. A negative control was made without the venom sample. The caseinolytic activity was 
expressed as $\mathrm{U} / \mathrm{mg}$, i.e. by the following formula: $\mathrm{A}_{\mathrm{U} / \mathrm{mg}}=\left(\Delta \mathrm{A}_{2} 80 / \mathrm{mg}\right.$ of venom $) \times 100$.

\section{Procoagulant Activity}

Coagulant activity was determined in human plasma (12). Citrated blood samples (1 volume of $129 \mathrm{mM}$ trisodium citrate and nine parts blood) were centrifuged at $1700 \mathrm{~g}$ for 15 minutes at $4^{\circ} \mathrm{C}$ and plasma was recovered. The coagulation activity was estimated after addition of venom serial dilutions. The minimum coagulant dose (MCD) was defined as the lowest amount of venom resulting in clot formation of human plasma through 1 minute at $37^{\circ} \mathrm{C}$.

\section{Phospholipase $A_{2}$ Activity}

The phospholipase $\mathrm{A}_{2}$ activity was determined according to the method of Holzer and Mackessy (13). Specific activity was expressed as follows: produced substrate $\mathrm{nM} / \mathrm{min} / \mathrm{mg}$ of venom.

\section{Hemorrhagic Activity}

Hemorrhagic activity was assessed as described by Kondo et al. (14) and modified by Theakston and Reid (12). Increasing venom doses (15 to 31 $\mu \mathrm{g})$ in $50 \mu \mathrm{L}$ of saline solution were injected by intradermal route (ID) in mice. Hemorrhagic measurements were recorded after two hours, according to the kinetics assay (after this time interval, the hemorrhagic areas are reabsorbed) (15). Diameters were measured and the minimum hemorrhagic dose (MHD) was defined as the venom dose that induced a lesion of $10 \mathrm{~mm}$ in diameter. All procedures involving the use of animals were approved by the Committee for the Ethical Use of Animals (10).

\section{Histological Study}

To analyze histopathological effects of venom, two groups of six mice were used. Each mouse received a sub-lethal dose of venom by intraperitoneal route (IP). The animal was sacrificed 60 minutes after venom injection. Organ tissues, 5 microns in thickness, were investigated through microscopic examination.

\section{Assay of Creatine Phosphokinase (CPK) in Blood}

Assay of creatine phosphokinase concentration (CPK) in blood was performed at three hours after venom injection. Serum was recovered immediately from blood by centrifugation. CPK measurement was performed according to the recommendations of the Chemistry Kodak Vitros System (USA).

\section{Fibrinogenolytic Activity}

Proteolytic activity upon fibrinogen was measured as described by Naves de Souza et al. (16) with some modifications. Fibrinogen solution $(2 \mathrm{mg} / \mathrm{mL})$ in $20 \mu \mathrm{L}$ (PBS) was incubated with venom dilution at $37^{\circ} \mathrm{C}$ for two hours. Fibrinogenic activity was stopped using $20 \mu \mathrm{L}$ of a solution containing $10 \%(\mathrm{v} / \mathrm{v})$ glycerol, $10 \%(\mathrm{v} / \mathrm{v})$ $\beta$-mercaptoethanol, 2\% (v/v) SDS and $0.05 \%$ $(\mathrm{w} / \mathrm{v})$ bromophenol blue. Fibrinogen hydrolysis was demonstrated using SDS-PAGE.

\section{Production of Antivenoms}

Monospecific antivenom was produced as follows. Horses were hyper-immunized subcutaneously with increasing doses of $\mathrm{Cc}$ or $\mathrm{Mm}$ venoms, at multiple sites around the neck. Complete Freund Adjuvant was used for primary immunization and incomplete Freund adjuvant for secondary immunization. Boosters were made using a saline solution ( $\mathrm{NaCl} 0.85 \%)$. Hyperimmunization program was assessed by injection of the same dose, at two-week intervals, until the antibody titer reached a high level. At the end of the immunization program, horses were bled, plasma proteins fractionated by precipitation with ammonium sulfate and immunoglobulins enzymatically digested to produce $\mathrm{F}\left(\mathrm{ab}^{\prime}\right)_{2}$ fragments. The fractions containing the $\mathrm{F}\left(\mathrm{ab}^{\prime}\right)_{2}$ fragments were extensively dialyzed against saline solution (17).

\section{Double Immunodiffusion to Control Specificity of the Antivenoms}

Double immunodiffusion assay was performed using slides containing $5 \mathrm{~mL}$ of $1 \%$ agarose (Sigma) in PBS pH 7.4. Wells were punched and filled with $20 \mu \mathrm{L}$ of $20 \mathrm{mg} / \mathrm{mL}$ of venom proteins or with $100 \mu \mathrm{L}$ of antivenom solution. After 48 hours of incubation at $37^{\circ} \mathrm{C}$, the slides were washed with $0.15 \mathrm{M} \mathrm{NaCl}$ for 72 hours, with the solution being changed every 12 hours, before drying at $37^{\circ} \mathrm{C}$ and staining with Coomasie Brilliant Blue R (Bio-Rad).

\section{Determination of Effective Doses $\left(E_{50}\right)$}

A fixed amount $\left(3 L_{50}\right)$ of venom was incubated with increasing volumes $(0$ to $300 \mu \mathrm{L})$ 
of antivenom, 30 minutes at $37^{\circ} \mathrm{C}$. Each mixture $(0.5 \mathrm{~mL})$ was injected by IP and IV routes into five mice. Deaths were recorded up to 48 hours. As a control, another group of mice received 3 $\mathrm{LD}_{50}$ of venom without antiserum treatment. Data were analyzed using the method of the software package Prism 45 (GraphPad, Inc.) and effective neutralization was expressed as effective dose $50 \%$ (ED50). ED50 was defined as the volume $(\mu \mathrm{L})$ needed to prevent death in $50 \%$ of the injected mice for the $3 \mathrm{LD}_{50}$ venom dose.

\section{RESULTS}

\section{Protein Content and Lethal Dose 50\% $\left(\right.$ LD $\left._{50}\right)$} of Snake Venoms

Swiss micewere used throughout this procedure to evaluate the toxicity of tested venoms. First, we estimated the protein concentrations, using BSA as the standard. Our results showed that $1 \mathrm{mg}$ of lyophilized venom contains $1000 \mu \mathrm{g}$ of $\mathrm{Mm}$ proteins and about $987 \mu \mathrm{g}$ of $C c$ proteins. Thus,

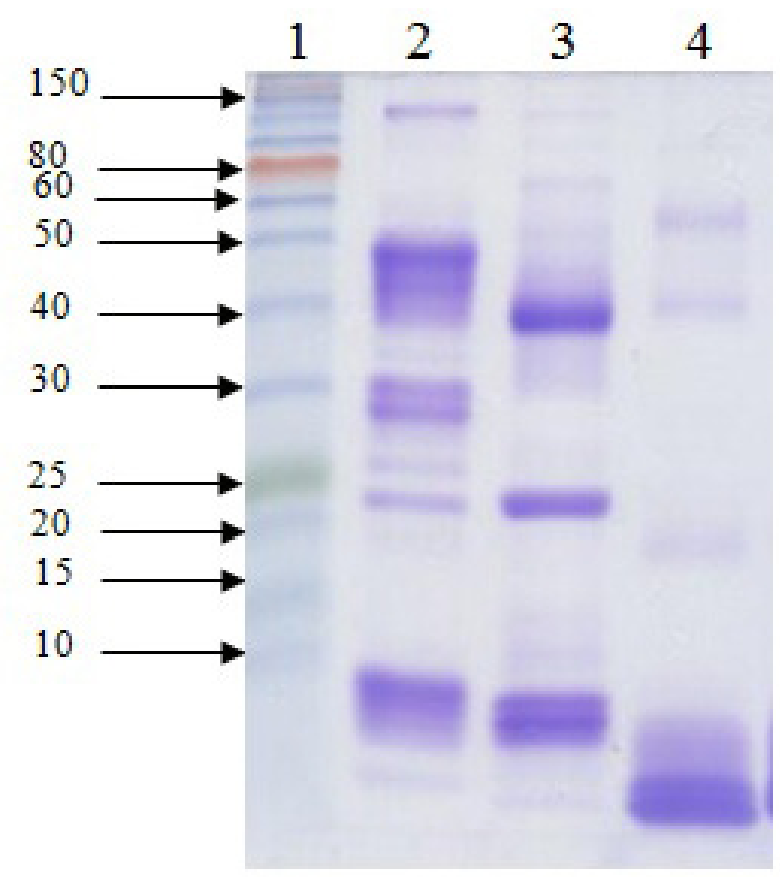

Figure 1. SDS-PAGE profiles of venoms. Electrophoretic separation of venom was performed on a vertical slab of $15 \%$ acrylamide under reducing conditions. Lane 1: molecular mass markers $(\mathrm{kDa})$; lane 2: Cerastes cerastes venom sample; lane 3: Macrovipera mauritanica venom sample; and lane 4: Naja haje venom sample. The markers indicated on the left are expressed as kDa. Gel was stained using Coomassie blue. we estimated that $1 \mathrm{mg}$ of venom has an average of $1 \mathrm{mg}$ of proteins. Herein, proteins correspond to the total dry weight of venom used to study biological effects.

Toxicity was assessed by IV injection of increasing venom amounts. The toxicity assessment was repeated three times. The $C c$ venom is the most toxic with an $\mathrm{LD}_{50}$ of 5.75 $\mu \mathrm{g} /$ mouse; $M m$ venom displays an $\mathrm{LD}_{50}$ that average $5.97 \mu \mathrm{g} / \mathrm{mouse}$. However, $B a$ venom is approximately 10 fold less toxic $\left(\mathrm{LD}_{50}\right.$ of $52.54 \mu \mathrm{g} /$ mouse).

\section{Biochemical Characterization of Cerastes cerastes and Macrovipera mauritanica Venoms}

The SDS-PAGE protein profiles were analyzed following Coomassie blue staining. Figure 1 shows that all venoms differ in composition. Each of the venoms from Cerastes cerastes and Macrovipera mauritanica contains a pool of proteins with different molecular weights. The Naja haje venom profile reveals protein bands of lower molecular weights.

\section{Proteolytic, Coagulant and Phospholipase A 2 Activities}

Casein substrate was used to determine the proteolytic activity displayed by snake venoms. According to the obtained results, proteolytic activity is estimated at $31.0 \pm 1.5 \mathrm{U} / \mathrm{mg}$ and $20.2 \pm$ $6.0 \mathrm{U} / \mathrm{mg}$ for of $\mathrm{Mm}$ and $C c$ venoms, respectively.

A procoagulant activity in human plasma was detected from both $\mathrm{Cc}$ and $\mathrm{Mm}$ venoms. Compared to the positive control value $(8.0 \pm 2.7$ $\mathrm{nM} / \mathrm{min} / \mathrm{mg}$, Crotalus durissus terrificus venom), $C c$ venom showed higher phospholipase activity $(25.0 \pm 3.0 \mathrm{nM} / \mathrm{min} / \mathrm{mg})$, when compared to $\mathrm{Mm}$ venom $(7.0 \pm 5.0 \mathrm{nM} / \mathrm{min} / \mathrm{mg})$ and $N h$ venom (6.7 $\pm 4.0 \mathrm{nM} / \mathrm{min} / \mathrm{mg})$ activities. Among all recorded phospholipase activities, we conclude that $C c$ venom presents the highest intensity.

\section{Hemorrhagic Activity}

Intradermal injection was used to estimate hemorrhagic potency of the venoms. Our results show that $C c$ and $M m$ venoms are endowed with a hemorrhagic feature. This activity is dosedependent (Figure 2).

The minimal hemorrhagic dose (MHD) is used to evaluate the hemorrhagic power. Our results demonstrated that an intradermal inoculation 


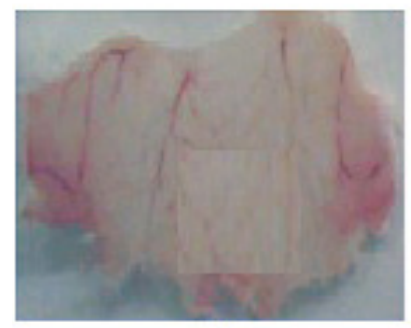

A

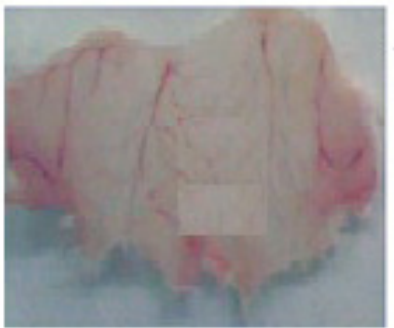

$A^{\prime}$

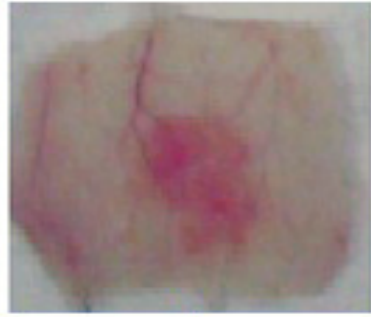

B

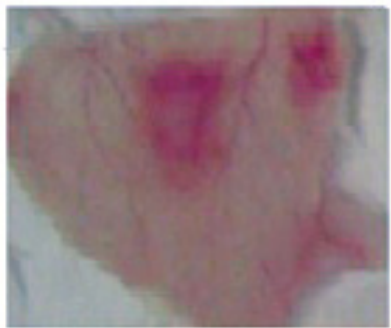

$B^{\prime}$

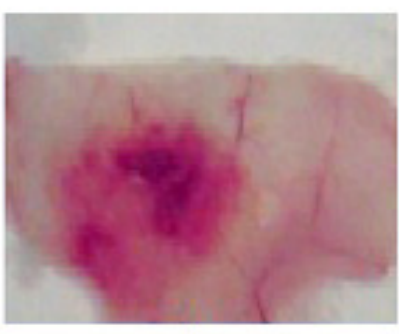

$\mathrm{C}$

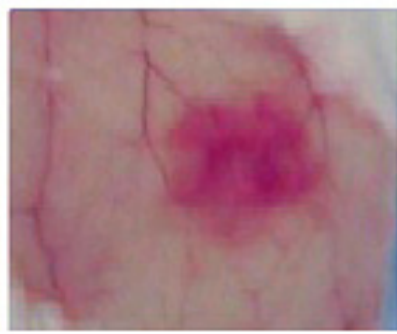

$C^{\prime}$

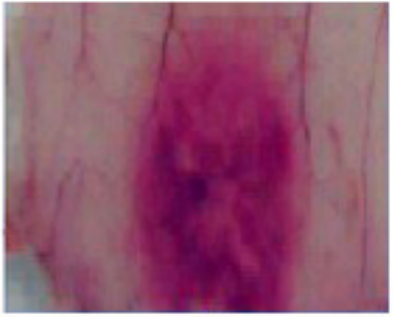

D

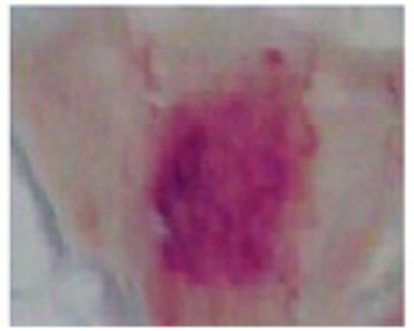

$D^{\prime}$

Figure 2. Recording of hemorrhagic activity of Cerastes cerastes ( $A, B, C, D)$ and Macrovipera mauritanica venoms $\left(A^{\prime}, B^{\prime}, C^{\prime}, D^{\prime}\right)$ of the "skin-test."This activity is dose dependent. $A$ and $A^{\prime}$ : control; $B$ and $B^{\prime}: 5 \mu \mathrm{g} ; C$ and $C^{\prime}: 10 \mu \mathrm{g} ; \mathrm{D}$ and $\mathrm{D}^{\prime}: 20 \mu \mathrm{g}$ of injected venom.
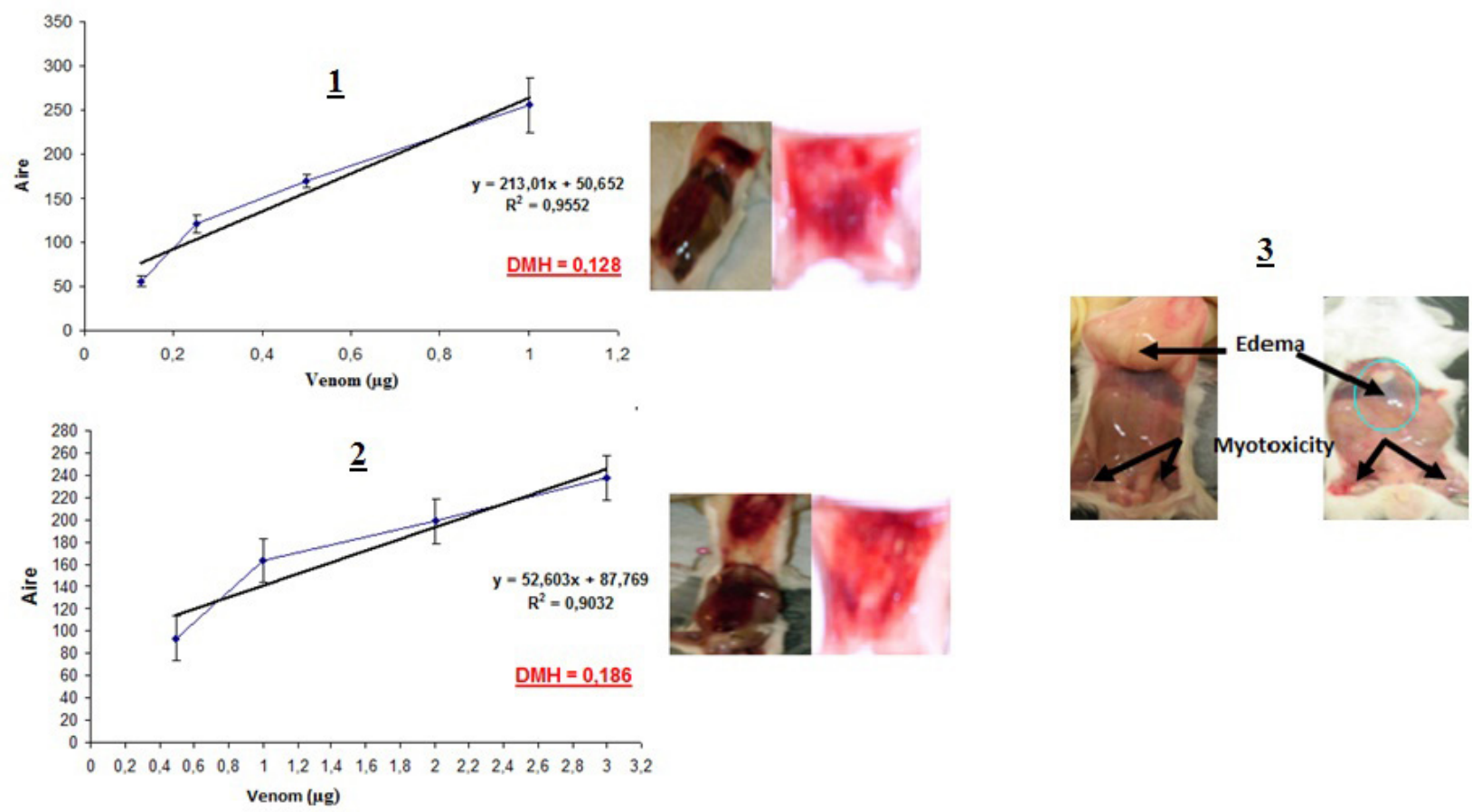

Figure 3. Minimum hemorrhagic dose (MHD) of (1) Macrovipera mauritanica; (2) Cerastes cerastes and (3) Naja haje venoms.

induces a strong hemorrhage with MHD of 0.13 and 0.63 in $\mu \mathrm{g} /$ mouse for $\mathrm{Cc}$ and $\mathrm{Mm}$ venoms, respectively. Nh venom has no hemorrhagic effect, despite the clear observation of edema and symptoms of myotoxicity (Figure 3 ).

\section{Effect of the Venom on Muscle Metabolism}

Evaluation of enzyme activity by means of measuring the creatine phosphokinase concentration in blood is the method used for estimating pathological effects such 
Control

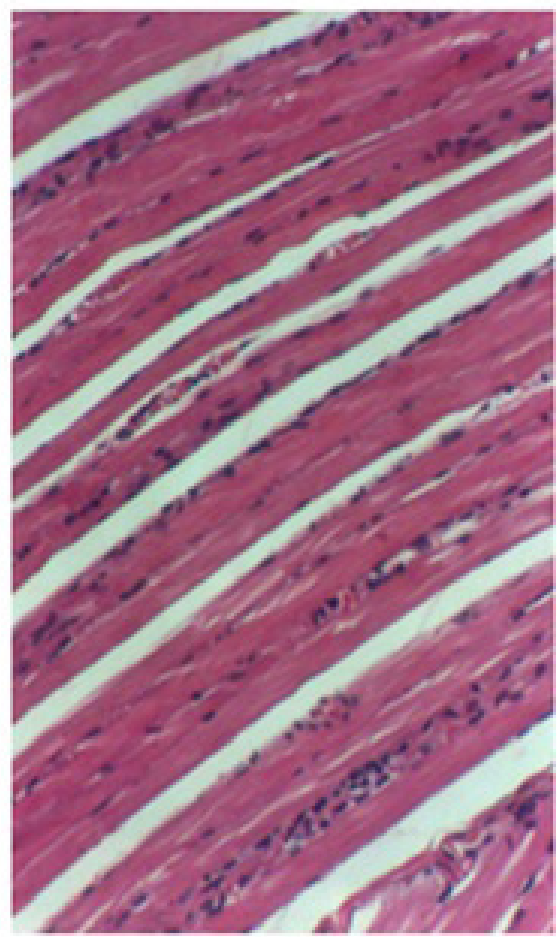

Cc venom

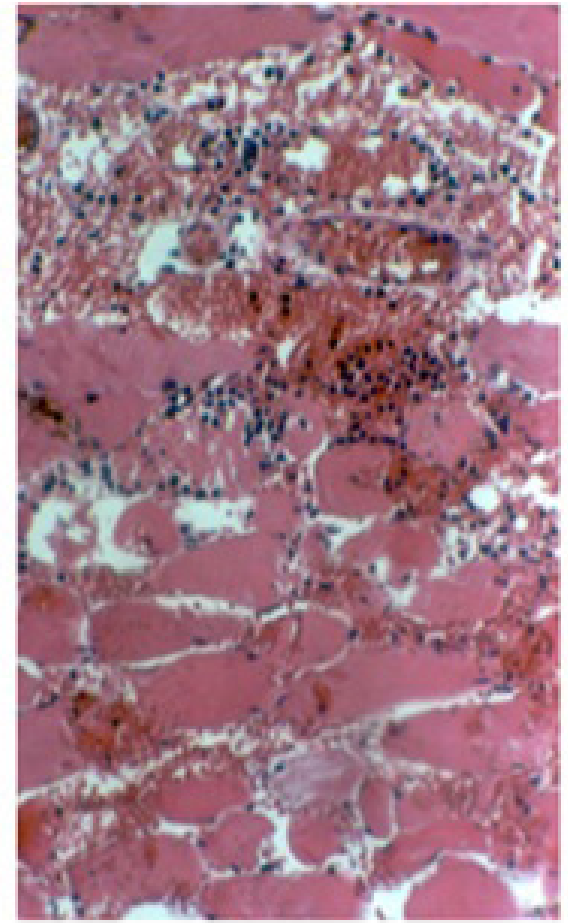

Mm venom

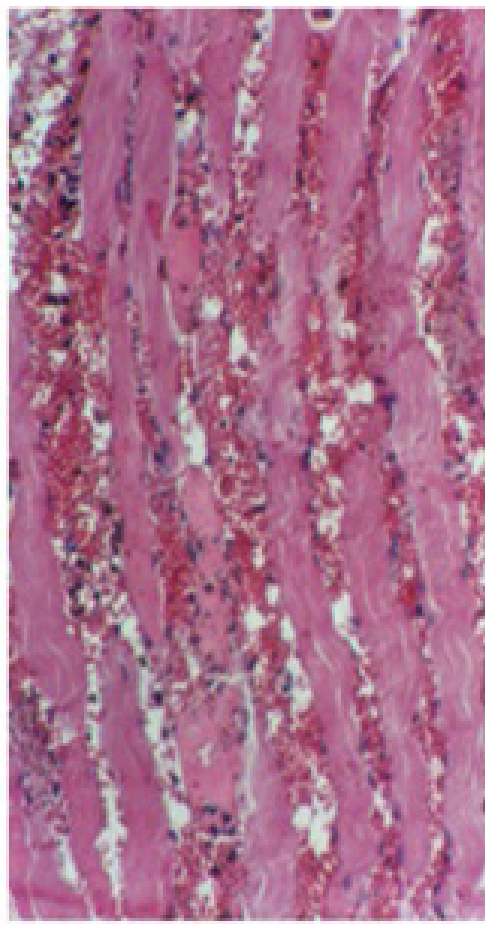

Figure 4. Effect of sublethal dose of Cerastes cerastes (Cc) and Macrovipera mauretanica $(\mathrm{Mm})$ venoms $(7 \mu \mathrm{g}$ of each venom/20 $\mathrm{g}$ mice) on the muscular tissue.

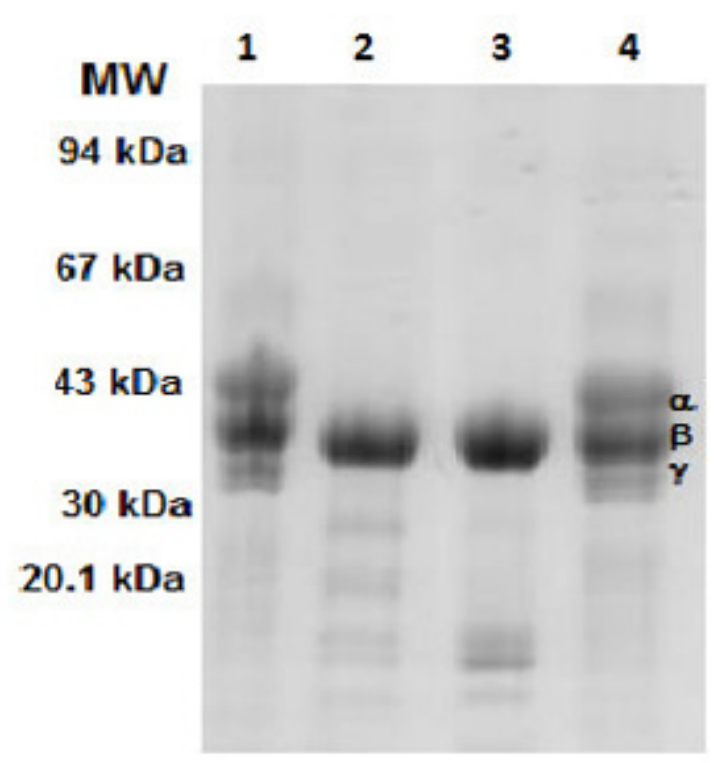

Figure 5. Fibrinogen degradation profile. Lane 1: Naja haje venom; lane 2: Cerastes cerastes venom; lane 3: Macrovipera mauritanica venom; and lane 4: fibrinogen. as myonecrosis. The serum $\mathrm{CPK}$ concentration is recorded three hours after induction of envenomation. For both $\mathrm{Cc}$ and $\mathrm{Mm}$ venoms, we observed a threefold increase of CPK serum concentration, a variation that is dependent on the venom dose.

\section{Change in Muscle Tissue of Mice}

Intramuscular injection of the venom caused tissue changes such as intense hemorrhages, edema, myonecrosis and inflammatory infiltrates. The observed intensity of alterations is more severe in the case of $C c$ venom (Figure 4).

\section{Fibrinogenolytic Activity}

Macrovipera mauritanica and Cerastes cerastes venoms act on two subunits of fibrinogen ( $\alpha$ and $\gamma$ ). This activity is not detected in Naja haje venom (Figure 5). Indeed, the ability of $\mathrm{Mm}$ and $C c$ venoms to degrade the $\alpha$ and $\gamma$ chains of fibrinogen was evident. However, $\beta$ chain degradation was not detectable. 


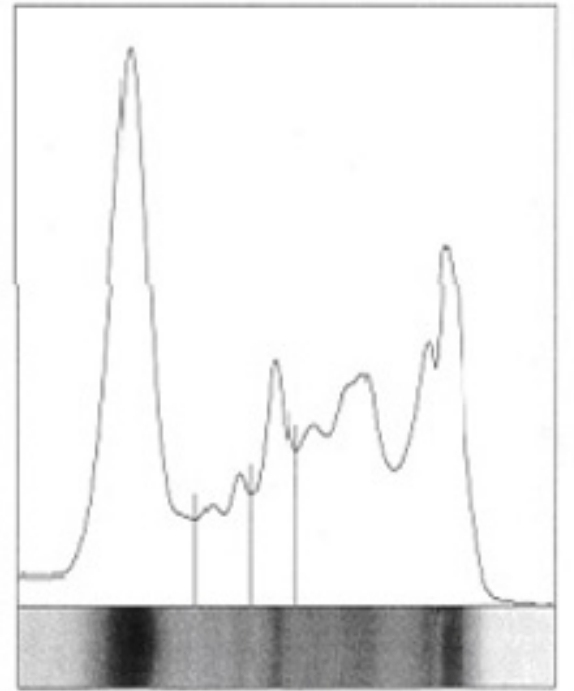

$\underline{A}$

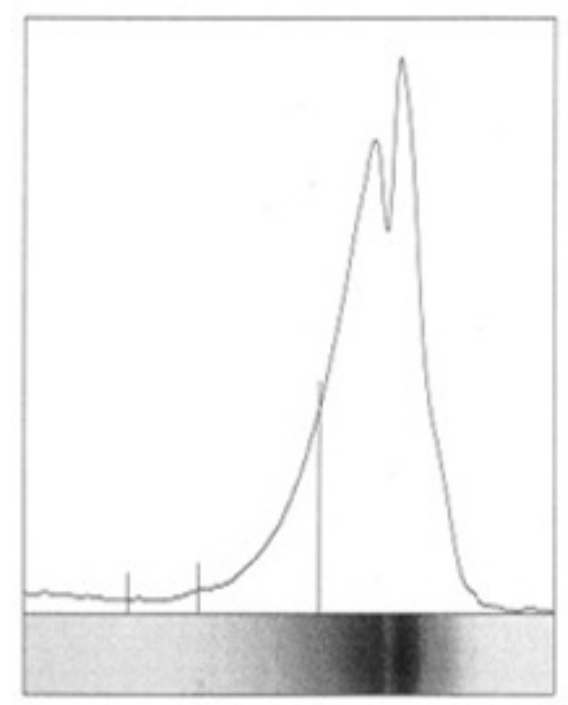

$\underline{B}$

\begin{tabular}{l|c|c} 
Fractions & $\%$ & $\mathrm{~g} / \mathrm{dL}$ \\
\hline Albumins & 38.1 & 3.44 \\
Alpha & 7.2 & 0.65 \\
Beta & 9.2 & 0.65 \\
Gama & 45.5 & 4.11
\end{tabular}

Total Proteins $=9.03 \mathrm{~g} / \mathrm{dL}$

\begin{tabular}{l|c|c} 
Fractions & $\%$ & $\mathrm{~g} / \mathrm{dL}$ \\
\hline Albumins & 3.2 & 0.22 \\
Alpha & 2.0 & 0.14 \\
Beta & 16.2 & 1.4 \\
Gama & 78.6 & 5.51
\end{tabular}

Total Proteins $=7.01 \mathrm{~g} / \mathrm{dL}$

Figure 6. Electrophoresis profile of (A) serum and (B) purified plasma containing the $F\left(a b^{\prime}\right)_{2}$. Analysis of results was made by software (SDS CELM 60 - software for densitometry scanner).

\section{Control of Antivenom Specificity}

A qualitative immunodiffusion assay was used to check antivenom specificity against any particular venom. Robust specific immunoprecipitation was observed among $C c$ venom and monospecific anti-Cc venom groups. A similar result was produced by $M m$ venom and its antivenom (Figure 6). For both monospecific antivenoms, the immunoprecipitation bands demonstrated the existence of specific antibodies against different venom proteins.

\section{Determination of Effective Doses (ED ${ }_{50}$ )}

In order to analyze the ability of monovalent $C c$ and $M m$ antivenoms to neutralize the lethal effect of $C c, M m$ and $B a$ venoms, in vivo experiments were performed. Table 1 shows that both monovalent antivenoms (i.e. anti- $C c$ and anti- $\mathrm{Mm}$, respectively) were able to neutralize the toxicity of venom molecules responsible for the lethality. Indeed, anti-Cc antivenom was more effective at neutralizing $B a$ venom with an $\mathrm{ED}_{50}$ of $84.3 \mu \mathrm{L} /$ mouse when compared to the 
Table 1. Determination of neutralizing effective doses (ED50) of $\mathrm{Cc}$ and $\mathrm{Mm}$ antivenoms in mice

\begin{tabular}{|c|c|c|}
\hline \multicolumn{3}{|l|}{$\mathrm{ED}_{50}$ in $\mu \mathrm{L}(95 \% \mathrm{Cl})$} \\
\hline Venom & Cc antivenom $(\mu \mathrm{L})$ & $M m$ antivenom $(\mu \mathrm{L})$ \\
\hline Cerastes cerastes $(C c)$ & 18.7 & 78 \\
\hline Macrovipera mauritanica $(\mathrm{Mm})$ & 62.4 & 48.3 \\
\hline Bitis arietans $(\mathrm{Ba})$ & 84.3 & 117.3 \\
\hline
\end{tabular}

anti- $M m$ capacity ( $\mathrm{ED}_{50}$ of $117.3 \mu \mathrm{L} /$ mouse).

The $C c$ antivenom more effectively neutralized $M m$ venom ( $\mathrm{ED}_{50}$ of $62.4 \mu \mathrm{L} /$ mouse) than $B a$ venom $\left(\mathrm{ED}_{50}\right.$ of $\left.84.3 \mu \mathrm{L} / \mathrm{mouse}\right)$. Similarly, the neutralizing capacity of $\mathrm{Mm}$ venom was higher than the capacities of $C c$ and, consequently, $B a$ $\left(\mathrm{ED}_{50}\right.$ of 78 and $117.3 \mu \mathrm{L} /$ mouse for $C c$ and $B a$ venoms, respectively). The best protective effect is obtained from the antivenom and venom that were used in the immunization program.

\section{DISCUSSION}

Snakebites constitute a common cause of injury and death in several regions of the world where they are considered an important public health problem. Their epidemiology is known only in a fragmentary way such that the number of poisoning cases is underestimated at 5 million per year with a mortality rate of $2.5 \%$ (18).

In Morocco, the fact that vipers are responsible for a large number of accidents may reflect the general abundance of this species and the increased level of direct contact. The accidents inflicted by these snakes are mainly characterized by hemorrhagic damage $(3,4)$.

The present study aimed to evaluate the biochemical, enzymatic and biological properties of venoms of the most dangerous Moroccan snakes, namely Cerastes cerastes and Macrovipera mauritanica. To study the cross-reactivity that may exist between the venoms, specific horse antivenoms were produced with the objective of identifying the best candidate or mixture for producing a highly protective antivenom to fight snake envenomation in North Africa.

First, dried venoms were biochemically investigated. Gel electrophoresis analysis demonstrated several protein bands certainly responsible for almost all of the observed biological effects $(6,19,20)$. Proteolytic activity, studied following the casein test, was low compared to other venoms reported in the literature (e.g. Philodryas venom). Phospholipase $\mathrm{A}_{2}$ activity is an important characteristic presented by $\mathrm{Cc}$ and $\mathrm{Mm}$ venoms. We estimated this activity to be four times higher in $\mathrm{Cc}$ venom than in $\mathrm{Mm}$ venom and in comparison to the positive control. Our results are in concordance with the recently reported studies $(6,21)$. PLA $_{2}$ has been purified and characterized since 1990 from Algeria Cerastes cerastes (22).

Cerastes cerastes and Macrovipera mauritanica venomsare characterized by their ability to degrade fibrinogen subunits (i.e. $\alpha$ and $\gamma$ chains). However, $\mathrm{Nh}$ (belonging to Elapidae family) venom does not display any detectable hemorrhagic activity. Nevertheless, we highlighted the presence of edema with symptoms of myotoxicity, very lower proteolytic and phospholipase activities and an absence of fibrinogenolytic activity.

Hemorrhaging is one of the most significant pathophysiological effects induced by vipers (23, 24). In this study, we have shown that injections of $\mathrm{Cc}$ or $\mathrm{Mm}$ venoms induce myonecrosis in skeletal muscles, which most likely was the result of myotoxin's direct action and hemorragin's indirect action. In muscle tissue, the myonecrosis induced a reduction of the serum CPK concentration (25).

$\mathrm{Cc}$ and $\mathrm{Mm}$ venoms were immunogenic and able to induce high levels of specific antibody titers when inoculated in horses. Indeed, monovalent anti- $\mathrm{Cc}$ and anti- $\mathrm{Mm}$ antivenoms cross-recognize several protein bands within $C c$ and $M m$ venoms and were able to cross-reactively recognize $B a$ venom. The data obtained from in vivo neutralization clearly indicated that both monovalent antivenoms (anti- $C c$ and anti- $M m$ ) contain a high ratio of specific antibodies capable of recognizing and undoubtedly neutralizing $\mathrm{Cc}$, $\mathrm{Mm}$ and $\mathrm{Ba}$ venom components. The use of $\mathrm{Cc}$ antivenom, which demonstrated better crossreactivity, is of major therapeutic interest. 


\section{CONCLUSION}

Cerastes cerastes and Macrovipera mauritanica venoms of Morocco are very toxic and contain several proteins that differ by molecular weights. Both venoms are characterized by not only high hemorrhagic and phospholipase $\mathrm{A}_{2}$ activities but also their ability to degrade the $a$ and $\gamma$ chains of fibrinogen. Our results highlight the high immunogenicity of $C c$, which leads to the induction of a horse antivenom that is highly protective against $C c, M m$ and $B a$ whole venoms. Indeed, this protective capacity is higher when compared to the $\mathrm{Mm}$-specific antivenom product.

\section{ACKNOWLEDGMENTS}

We are grateful to Dr. J. P. Chippaux for valuable suggestions and helpfulness during the preparation of the manuscript. We are indebted to Dr. L. Boussadda (Responsible for the Animal Unit of the Pasteur Institute of Morocco) for providing ophidian venoms. We are grateful to Ms. F. Chgoury for technical assistance.

\section{COPYRIGHT}

(c) CEVAP 2012

\section{SUBMISSION STATUS}

Received: September 25, 2012.

Accepted: November 6, 2012.

Abstract published online: November 9, 2012.

Full paper published online: November 30, 2012.

\section{CONFLICTS OF INTEREST}

The authors declare no conflicts of interest.

\section{FINANCIAL SOURCE}

This research was supported by the Pasteur Institute of Morocco which is a public institution under the Ministry of Health.

\section{ETHICS COMMITTEE APPROVAL}

All the procedures involving animals were in accordance with the ethical principles in animal research adopted by the World Health Organization (10).

\section{CORRESPONDENCE TO}

Noreddine Ghalim, Pasteur Institute of Morocco, 1 Place Louis Pasteur, 20360-Casablanca, Morocco. Phone: +2126758420 68. Fax: +212 5 222609 57. Email: nghalim@yahoo.fr.

\section{REFERENCES}

1. Chippaux JP, Goyffon M. Venoms, antivenoms and immunotherapy. Toxicon. 1998;36(6):823-46.

2. Chippaux JP, Goyffon M. Envenimations et intoxications par les animaux venimeux ou vénéneux. I. Généralités. Med Trop. 2006;66(3):215-20.

3. Chafiq F, Rhalem N, Ouammi L, Fekhaoui M, Semlali I, Soulaymani A, et al. Profil épidémiologique des cas de morsures de serpents déclarés au Centre Anti Poison du Maroc (1980 à 2008). Publication officielle du centre anti poison du Maroc. Ministère de Santé. 2011;9:6-10.

4. Chani M, L'kassimi H, Abouzahir A, Nazi M, Mion G. Three case-reports of viperin envenoming in Morocco. Ann Fr Anesth Reanim. 2008;27(4):330-4.

5. Chippaux JP, Lang J, Amadi Eddine S. Treatment of snake envenomations by a new polyvalent antivenom composed of highly purified $\mathrm{F}(\mathrm{ab}) 2$ : results of a clinical trial in northern Cameroon. Am J Trop Med Hyg. 1999;61(6):1017-18.

6. Rocha MM, Paixão-Cavalcante D, Tambourgi DV, Furtado Mde F. Duvernoy's gland secretion of Philodryas olfersii and Philodryas patagoniensis (Colubridae): neutralization of local and systemic effects by commercial bothropic antivenom (Bothrops genus). Toxicon. 2006;47(1):95-103.

7. Quesada L, Sevcik C, Lomonte B, Rojas E, Gutiérrez JM. Pharmacokinetics of whole IgG equine antivenom: comparison between normal and envenomed rabbits. Toxicon. 2006;48(3):255-63.

8. Markwell M, Haas SM, Bieber LL, Tolbert NE. A modification of the Lowry procedures to simplify protein determination in membrane and lipoprotein samples. Anal Biochem. 1978;87(1):206-10.

9. Laemmli UK. Cleavage of structural proteins during the assembly of the head of bacteriophage T4. Nature.1970; 227:680-85.

10. World Health Organization. Progress in the characterization of venoms and standardization of antivenoms. WHO Offset Publication.1981;58:1-44.

11. Lomonte B, Gutiérrez JM. La actividad proteolítica de los venenos de serpientes de Costa Rica sobre la caseína. Rev Biol Trop. 1983;31(1):37-40.

12. Theakston RDG, Reid HA. Development of simple standard assay procedures for the characterization of snake venoms. Bull World Health Organ. 1983;61(6):949-56.

13. Holzer M, Mackessy SP. An aqueous endpoint assay of snake venom phospholipase $\mathrm{A}_{2}$. Toxicon. 1996;34(10):1149-55.

14. Kondo H, Kondo S, Ikesawa I, Murata R, Ohsaka A. Studies of the quantitative method for determination of hemorrhagic activity of Habu snake venom. Jpn J Med Sci Biol. 1960;13:43-52.

15. Furtado MFD. Biological and immunological properties of the venom of Bothrops alcatraz, an endemic species of pitviper from Brazil. Comp Biochem Physiol C Toxicol Pharmacol. 2005;141(2):117-23.

16. Naves de Souza DL, Gomes MS, Ferreira FB, Rodrigues RS, Achê DC, Richardson $M$, et al. Biochemical 
and enzymatic characterization of BpMP-I, a fibrinogenolytic metalloproteinase isolated from Bothropoides pauloensis snake venom. Comp Biochem Physiol B Biochem Mol Biol. 2012;161(2):102-9.

17. Raw I, Guidolin R, Higashi H, Kelen E. Antivenins in Brazil: preparation. In: Tu AT (editor). Handbook of natural toxins. Vol. 5. New York: Marcel Dekker; 1991. p.557-83.

18. Chippaux JP. Snake-bites: appraisal of the global situation. Bull World Health Organ. 1998;76(5):51524.

19. Fahmi L, Makran B, Plá D, Sanz L, Oukkache N, Lkhider $\mathrm{M}$, et al. Venomics and antivenomics profiles of North African Cerastes cerastes and $C$ vipera populations reveals a potentially important therapeutic weakness. J Proteomics. 2012;75(8):2442-53.

20. Makran B, Fahmi L, Plá D, Sanz L, Oukkache N, Ghalim N, et al. Snake venomics of Macrovipera mauritanica from Morocco, and assessment of the para-specific immunoreactivity of an experimental monospecific and a commercial antivenoms. J Proteomics. 2012;75(8):2431-41.

21. Warrel DA. Guidelines for the management of snake-bites. World Health Organization. Library Cataloguing-in-Publication data; 2010.
22. Djebari FL, Martin-Eauclaire MF. Purification and characterization of a phospholipase $\mathrm{A}_{2}$ from Cerastes cerastes (horn viper) snake venom. Toxicon. 1990; 28(6): 637-46.

23. Hamza L, Gargioli C, Castelli S, Rufini S, Djebari FL. Purification and characterization of a fibrinogenolytic and hemorrhagic metalloproteinase isolated from Vipera lebetina venom. Biochimie. 2010;92(7):797805.

24. Gutiérrez JM, Géne JA, Rojas G, Cerdas L. Neutralization of proteolytic and hemorrhagic activities of Costa Rica snake venoms by a polyvalent antivenom. Toxicon. 1985;23(6):887-93.

25. Boukhalfa AH, Meksem A, Laraba-Djebari F. Purification and biochemical characterization of a novel hemorrhagic metalloproteinase from horned viper (Cerastes cerastes) venom. Comp Biochem Physiol C Toxicol Pharmacol. 2009;150(2):285-90. 